\title{
Ĕgitim Fakültesinde Öğrenim Gören Öğretmen Adaylarının Narsisizm Düzeylerinin Siber Zorbalığa Duyarlık ve İnternet Bağımlılığı Düzeylerine Etkisi* $^{*}$
}

\section{The Effect of Prospective Teachers' Narcissism Levels on Cyber Bullying Sensitivity and Internet Addiction Levels}

\author{
Miray ÖZÖZEN DANACI \\ İzmir Demokrasi Üniversitesi \\ miray.ozozen@idu.edu.tr \\ Nurdan KAVAKLI \\ İzmir Demokrasi Üniversitesi \\ nurdan.kavakli@idu.edu.tr \\ Gülșah TIKIZ \\ İzmir Demokrasi Üniversitesi \\ gulsah.tikiz@idu.edu.tr
}

Alıntılama: Özözen Danacı, M., Kavaklı, N., Tıkız, G. (2018). Eğitim fakültesinde öğrenim gören öğretmen adaylarının narsisizm düzeylerinin siber zorbalığa duyarlık ve internet bağımlılığı düzeylerine etkisi. Ulusal Eğitim Akademisi Dergisi (UEAD), 2(2), 86-98.

Geliş tarihi:

15 Ağustos 2018

Kabul tarihi:

26 Ekim 2018

Sorumlu yazar:

Miray ÖZÖZEN

DANACI

miray.ozozen@idu.edu.tr

(C) 2018 UEAD.

Bütün hakları saklıdır.
Özet: Son yüzyılda bilgi ve iletişim teknolojilerinde görülen hızlı gelişmeler, internet kullanma oranını artırarak hayatı kolaylaştırmanın yanında birtakım riskleri de beraberinde getirmektedir. İnternetin, amacını aşan şekilde ve aşırı kullanımını ifade eden internet bağımlılığının ve bilgi ve iletişim teknolojileri kullanılarak yapılan zarar verme davranışları olarak tanımlanan siber zorbalığın da bu riskler arasında yer aldığı ifade edilmektedir. Bireyin, insanları ve yaşamı algılama ve değerlendirme biçiminde olumsuz yönde etkileyen narsisistik kişilik yapısının ise, bireylerin düşünce, davranış ve tutumlarını etkilediği bilinmektedir. Bu nedenle bu araştırmada; öğretmen adaylarının sahip oldukları narsisizm düzeylerinin siber zorbalığa duyarlık ve internet bağımlılı̆̆ düzeylerini etkileyip etkilemediği araştırılmıştır. Araştırmanın evrenini Batı Karadeniz bölgesindeki üniversitelerin eğitim fakültelerinde öğrenim gören temel eğitim öğretmen adayları, örneklem grubunu ise, Hacettepe Üniversitesi Eğitim Fakültesi Temel Eğitim bölümünde öğrenim gören 142 kız ve 83 erkek olmak üzere toplam 225 öğretmen adayı oluşturmaktadır. İlişkisel tarama modelli olarak yürütülen araştırmada veri toplama araçları olarak; araştırmaya katılanların demografik bilgilerini elde etmek amacıyla araştırmacılar tarafindan oluşturulan "Demografik Bilgi Formu", Young (1996) tarafindan geliştirilen ve Bayraktar (2001)'ın Türkçe’ye uyarladığg 'İnternet Bağımlılık Ölçeği”, Ames ve diğerleri (2006) tarafından yeniden revize edilen "Narsistik Kişilik Envanteri" (NKE) ve Tanrıkulu ve diğerleri (2011) tarafindan geliştirilen, "Siber Zorbalığa İlişkin Duyarlılık Ölçeği” kullanılmıştır. Siber zorbalığın, internet bağımlılığı ve narsisizmle ile pozitif yönlü anlamlı ilişkisi bulunduğu görülmüştür. Regresyonun aracılık testine ait siber zorbalık ile internet bağımlılığı arasında narsisizm etkisine yönelik bootstrapping katsayı sonuçları, internet bağımlılığı düzeyinin siber zorbalığı

\footnotetext{
* Bu çalışmanın bir kısmı, 02-06 Eylül 2018 tarihleri arasında Girne, Kıbrıs’ta düzenlenen 'ICLEC: 1st International Conference on Language, Education and Culture' adlı konferansta sunulmuştur.
} 


\begin{abstract}
$\mathrm{BSH}=.22$ ve narsisizmi $\mathrm{BSH}=.41$ doğrusal açıdan etkilediğini göstermiştir. Araştırmadan elde edilen verilere bağlı olarak siber zorbalığa ve internet bağımlılığına yönelik önlemsel çalışmalarda öncelikle narsisistik odaklı karakter ve kişilik yapısının kontrol altına alınması gerektiği, yordayıcı özellikler konusunda sağaltım ve terapi süreçlerinin desteklenmesi gerekliliği ortaya konmuştur.

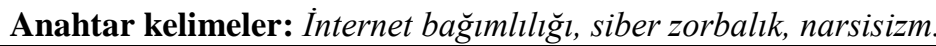

Received:

15 August 2018

Accepted:

26 October 2018

Corresponding author:

Miray ÖZÖZEN

DANACI

miray.ozozen@idu.edu.tr

(C) 2018 UEAD.

All rights reserved.

Abstract: The rapid developments in information and communication technologies in the last century have increased the internet usage rate, and this makes life easier although it has brought about some risks along with it. Cyberbullying, which is also defined as internet addiction that involves the excessive use of the internet and goes beyond its aim for the purpose of using damaging behaviors via using information and communication technologies is considered to be among these risks. It is known that the narcissistic personality structure, which negatively affects the individual' life, people and life in general, also has an impact on the thoughts, behaviors and individuals' atittudes. Within the body of this research, it has been investigated whether narcissism levels of the prospective teachers affect cyberbullying sensitivity together with the internet addiction levels. The population of the study include primary education prospective teachers studying at the faculties of education at the universities in Western Black Sea Region. On the other hand, the sample of the study includes 142 female and 83 male students (total 225 prospective teachers) studying at the Department of Primary Education, Hacettepe University. The study exploited correlational survey model, and the data were collected through "Demographical Information Form" to gather demographic information of the participants. Besides, "Internet Addiction Scale" which was developed by Young (1996) and adapted into Turkish by Bayraktar (2001) together with the "Narcissistic Personality Inventory" revised by Ames et al. (2006) and "Cyberbullying Sensitivity Scale" developed by Tanrıkulu et al. (2011) were utilized in the study. It has been observed that there is a positive correlation between internet addiction, narcisisism and cyberbullying. The results of the bootstrapping coefficient for the narcissism effect of cyberbullying and internet addiction on the regression mediation test showed that the level of internet addiction affects the cyberbullying $\mathrm{BSH}=.22$ and the narcissism BSH=.41 linearly. The results of the study also revealed that people with an inclination towards narcissistic personality type should be treated cautiously, and there mushrooms the necessity of a supporting treatment together with the required therapy sessions which are to be fostered as predictive traits.
\end{abstract}

Keywords: Internet addiction, cyberbullying, narcissism.

\title{
1. Giriş
}

Yaşamı kolaylaştırmak amacıyla tasarlanan bilişim teknolojileri, faydaları ile beraber olumsuzlukları ve problemleri de beraberinde getirmiştir. İnternet bağımlılığı ile siber zorbalık bu sorunlar içerisinde yer almaktadır. İnternet bağımlılığı ile siber zorbalık günümüz kamuoyunda da çok sıkça duyulan sorunlar olmuş ve psikoloji/psikiyatri merkezlerine internet bağımlı̆̆ sebebiyle başvuranlar artmış, okulların rehberlik birimlerinde internet bağımlılığı ve siber zorbalık problemi şikayetleri artan bir biçimde gündeme gelmiştir. Son yüzyılda teknoloji ile sağlanan olanaklar, meslek sektörlerinde teknolojik kullanımın artması ve yeni neslin teknolojiyi yaygın kullanmak durumunda olması, geleneksel zorbalık kavramının içerisine teknoloji üzerinden uygulanan bir sanal zorbalık türünü ortaya çıkarmıştır (Ayas \& Horzum, 2011; Chibbaro, 2007; Dake, Price, Telljohann \& Funk 2003).

Geleneksel zorbalık, açık olarak fiziksel davranışları (dövme gibi), sözel istismarı (lakap takma) ve toplumdan izole etme çabası ve dedikodular üretme şeklinde davranışları içermektedir 
(Kowalski \& Limber, 2007). Bilgi ve iletişim teknolojilerinin kötüye kullanılması sonucu ortaya çıkan siber zorbalık, yani sanal zorbalık ise literatürde yer alan farklı tanımlara göre; internet, iletiler, e-mail, telefon, mesaj, sohbet siteleri, web siteler ve sosyal şebekeler gibi iletişim araçlarının ile kasıtlı ve tekrarlı biçimde, başka bireylere zarar verme amaçlı kullanılması şeklinde açıklanmaktadır (Dake et al., 2003; Hinduja \& Patchin, 2008; Juvonen \& Gross 2008; Peker, 2014; Rivers \& Noret, 2010; Smith et al., 2008; Tokunga, 2010; Wang, 2015; Willard, 2007).

Geleneksel zorbalık biçiminde çoğunlukla güçsüz kurbanlar tercih edilmektedir ancak siber zorbalık türünde bu durum zorunlu değildir (Vandebosh \& Cleemput, 2007; Willard, 2007). Siber zorbalık türünü klasik/geleneksel zorbalık türünden ayırt eden nitelikler; gizliliğe uygunluk, mekan ve süre kısıtlamasının bulunmaması, fiziksel güç gerektirmemesi, mağdur kişiye kolayca ulaşabilme, etkisel alanın genişliği ve teknolojik olanaklarla mağdur bireyi kolayca baskı altına alma, mağdurla içerisinde bulunulan fiziksel sınırlar içerisinde kalmayarak her saat her dakika uygulanabilmesidir (Campbell, 2005; Li, Cross \& Smith, 2012).

İnternet bağımlılarının ortalama kullanıcılara oranla daha fazla nevroza yönelimli ve daha düşük düzeyde dışadönük oldukları, sosyalleşme açısından daha endişeli ve yalnız olmakla birlikte nevrotizme dayalı kişilik yapılarına sahip oldukları yapılan araştırmalarla ortaya konmuştur (Campbell, 2005; Li, 2007; Yaman, Eroğlu \& Peker, 2011). Dolayısıyla internet bağımlılığı ve siber zorbalık olguları bireylerin kişiliği ile yakından ilişkili olabilmektedir.

Nevrotik duygu bozukluğu türevi olan "Narsisizm" kavramı, Yunan mitolojisinde, suda yansımasını gördükten sonra, yansımasına aşık olan ve ömrünün sonunda dek ulaşması imkansız bu aşkın peşinde kendine koşarken hayatını harcayan Narkissos'tan ortaya çıkmıştır (Karaaziz \& Erdem-Atak, 2013). Patalojik yönüyle narsisizm, kişinin megalomanca ve başka bireyleri dikkate almadan, empatiden yoksun, bencilce bir tavırla egosunun, diğer bireylerin duygu, düşünce ve övgüleriyle desteklenmesine ihtiyaç duyması biçiminde görülmektedir (Akhtar, 1989; Kernberg, 1975).

Aristoteles, 'Bir insan nasıl bir birey ise, amacı da herkese öyle görünmektedir; kişi iyi yargılarda bulunarak, iyiyi seçecekse; yetenekli birey doğuştan bu güce sahiptir, bu çevreden edinilecek bir şey değildir, natürel açıdan edinilecek bir durumdur.' şeklinde açıklamaktadır. Sonraki ahlâkî gelişme ve insanlara yaklaşımı, öğretisi sahip olduğu bu doğal yapı doğrultusunda gerçekleşecektir. Bu ruhsal düşünce tarzları bireyin kendisini, diğer insanları ve evreni algılama ve değerlendirme türünü etkileyebilmektedir. Narsisistik bireylerin, özel hak ve ayrıcalığa sahip olduklarına inanmaları, empati kuramamaları ve eleştiriye kapalı olmaları en önemli özellikleridir. Dolayısıyla bu özellikleri sebebiyle bireylerin narsisizm eğilim düzeyleri zorbalık ve internet bağımlılı̆̆ı düzeylerini de etkileyebilmektedir (Parman, 1996; Twenge \& Campbell, 2010).

Bireylerin davranışları ve bu davranışlar sonucunda oluşan karakter ve kişilik yapıları salt kişiyi etkilemekten öte, toplum, kültür ve insan ilişkilerinde etkide bulunan bir yapıdadır. Yapılan pek çok araştırmada narsisizmin, yaşamın sihirli yılları olan okul öncesi dönemde kazanıldığı ifade edilmiş ve dolayısıyla bu döneme damga vuran okul öncesi öğretmenlerinin narsisizm düzeylerinin de sorgulanması ihtiyacını doğurmuştur. Ayrıca çocuklara narsistik bakış açısı ile yaklaşmalarının yanı sıra geleceğin yapı taşı olan çocukların emanet edileceği bireyler olarak öğretmenlerin narsisizm düzeyleri ve buna yönelik etki mekanizmaları önem arz etmektedir.

Çocukların küçük yaşlarda karakter oluşumunda ve insani değerlerinin yapılandırılmasında öneme sahip olan okul öncesi öğretmenlerinin kendilerinin sahip oldukları insani değerler çocuklara sağlayacakları açısından önem arz etmektedir. Tahmin edilenden daha 
yaygın olan ve her yaşta bireyi etkileyebilen bir sorun olan siber zorbalık, gerek mağdur gerekse siber zorbalık uygulayan kişiler açısından duygu, davranış, sağlık, eğitim ve iletişim açısından olumsuz sonuçlar ile yakın ilişkili olmaktadır. Bu bağlamda narsistik karakterin siber zorbalık için bir neden oluşturabileceği göz önünde bulundurulabilmektedir.

Konuya ilişkin literatür incelendiğinde, siber zorbalık hakkında etiyolojik ve tanımlayıcı pek çok araştırmanın bulunduğu görülmektedir (Bhat, 2008; Cassidy et al., 2009; Hoff \& Mitchell, 2009; Rivers \& Noret, 2010; Smith et al., 2008; Vandebosch \& Van Cleemput, 2009; Varjas, Henrich \& Meyers, 2009; Willard, 2007). Bunlara göre, siber zorbalık çoğunlukla, ayrılık, kıskanma, hoşgörü yoksunluğu ve çeteleşme gibi iletişim ve ilişkisel problemlerden oluşmaktadır. Siber zorbalığın temel çıkış noktası olan kıskançlık durumunun narsisistik bireylerde görülüyor olması ve siber zorbalık yapan kişilerin internet kullanma düzeylerinin yüksek olması bu üç kavramın biribiri arasında etki mekanizması olabilme sorunsalını ortaya çıkarmıştır (Hoff \& Mitchell, 2009; Willard 2007).

$\mathrm{Bu}$ nedenle araştırmada, meslek yaşamı boyunca eğitsel açıdan topluma etki etmesi nedeniyle öğretmen adaylarının internet bağımlılık düzeyleri ile siber zorbalık ile narsisizm eğilim düzeyleri arasındaki ilişki yordanmıştır.

\section{Yöntem}

\subsection{Araştırma Modeli}

Araştırmada, genel tarama modelleri arasından ilişkisel tarama modelli biçiminde yürütülmüştür. İlişkisel tarama modelinde iki ve ya daha fazla sayıda değişkenler arası bütünsel değişimin varlığını ve/veya düzeyini tespit etmek amacı taşıyan araştırma modeli türüdür. Bu kapsamda öğretmen adaylarının internet bağımlılık düzeyleri ile siber zorbalık ve narsistik kişilik eğilim düzeyleri arasındaki ilişki incelenmiştir (Balc1, 2005; Karasar, 2014). Araştırmanın bağımlı değişkeni siber zorbalığa duyarlık ve narsisizm düzeyidir. Araştırmanın bağımsız değişkenleri ise internet bağımlılığı, cinsiyet, yaş, algılanan ekonomik durumdur.

\subsection{Evren ve Örneklem}

Araştırmanın evrenini Batı Karadeniz bölgesindeki üniversitelerin eğitim fakültelerinde öğrenim gören öğretmen adayları, çalışma grubunu ise Hacettepe Üniversitesi Eğitim Fakültesi temel eğitim bölümünde öğrenim gören ve farklı illerden gelmiş olan öğretmen adayları oluşturmaktadır. Çalışma grubu 142 kız ve 83 erkek olmak üzere toplam 225 öğretmen adayından oluşmaktadır.

\subsection{Veri Toplama Araçları}

$\mathrm{Bu}$ araştırmada öğretmen adaylarının internet bağımlılık düzeylerinin belirlenmesi amacıyla "İnternet Bağımlılık Ölçeği”, narsisistik kişilik eğilimlerinin belirlenmesi amacıyla "Narsistik Kişilik Envanteri" ve siber zorbalık düzeyi değerlendirmeleri için 'Siber Zorbalığa İlişkin Duyarlılık Ölçeği’ kullanılmıştır. Öğretmen adaylarının özlük nitelikleriyle ilgili bilgileri elde etmek için araştırmacılar tarafından hazırlanan "Kişisel Bilgi Formu” kullanılmıştır. Aşağıda veri toplama araçlarına ilişkin bilgiler yer almaktadır.

Araştırmanın bağımsız değişkenlerine ilişkin veri toplamak amacıyla araştırmacılar tarafindan uzman görüşü alınarak hazırlanan 'Kişisel Bilgi Formu' oluşturulmuştur. Kişisel Bilgi Formunda araştırmanın bağımsız değişkenlerinin her biri için ayrı sorularla bilgi alınması 
amaçlanmıştır. Sorular kapalı uçlu olarak hazırlanmış, cevaplar sorunun olası cevaplarına göre değişken sayıda seçenekli olarak verilmiştir. Formda, öğretmen adaylarının cinsiyet, bölüm, algılanan ekonomik durum, internet kullanım amacı ve süresi ele alınmıştır.

Young (1996) tarafından, DSM-IV'ün "Patalojik Kumar Oynama” ölçütlerinden uyarlanarak oluşturulan "Tanı Anketi" daha sonra geliştirilmiş ve 20 soruluk bir "İnternet Bağımlılık Ölçeği” (IBÖ) oluşturulmuştur. Bayraktar (2001) tarafından Türkçe'ye uyarlanan ölçek, 12 - 17 yaş grubu ergenlerin internet bağımlılık düzeylerini değerlendirebilecek özelliktedir. Ölçeğin standardizasyonu yapılmış Alpha değeri yönünden güvenirliği, .91 Spearman-Brown değeri yönünden güvenirliği ise; .87'dir. "İnternet Bağımlılık Ölçeği”nde katılımcılardan "Hiçbir zaman" "Nadiren" "Arada sırada" "Çoğunlukla" "Çok sık" ve "Devamlı" seçenekleri arasından bir tanesini işaretlemeleri istenmektedir. Bu seçeneklerin toplanması sonucunda 80 ve üstü puan alan katılımcılar "internet bağımlısı" şeklinde açıklanmaktadır. 50-79 arasında puanlar alanlar "sinırlı semptom gösterenler", 50 puan altında alanlar "semptom göstermeyenler" olarak açıklanmıştır.

İlk olarak Raskin ve Hall (1979) tarafindan 54 madde halinde geliştirilen "Narsistik Kişilik Envanteri"nden (NKE) daha sonra madde ve faktör analizleri sonucunda 40 maddeden oluşan formu geliştirilmiştir (Raskin \& Terry, 1988). 2005 yılında Ames ve arkadaşları tarafindan 16 madde ile yeniden düzenlenen NKE yaygın olarak kullanılmaya başlanmıştır. NKE'nin 16 soruluk formunun Türkçe geçerlik-güvenirlik çalışması Atay (2009) tarafından yapılmıştır. Ölçeğe katkı sağlamadığı anlaşılan dört ifadede revizyona gidilmesinin ardından ölçeğin güvenirlik katsayısı olan Cronbach alfa değerinin .63 olduğu tespit edilmiştir. Yapılan faktör analizi sonucunda ölçeğin orijinal haline uygun biçimde altı faktör yapısına sahip olduğu gözlenmiştir. Bu faktörler; otorite, kendine yeterlik, üstünlük, teşhircilik, hak iddia etme ve sömürücülüktür.

Tanrıkulu, Kınay ve Arıcak (2013) tarafından geliştirilen "Siber Zorbalığa İlişkin Duyarlılık Ölçeği”, 15 maddeden oluşmaktadır. Örneklem büyüklüğünün arttırılması ile tekrarlanan analizlerde yeterli yük değeri içermeyen iki madde ölçek içerisinden çıkarılmış ve ölçek son olarak revize edilmiştir. Son olarak 13 madde, tek faktörden oluşan ölçek, tüm varyansın \%46'sını göstermektedir. 3'lü likert tipi ölçekte, maddelerden yüksek puan alınması siber zorbalık duyarlılığının yüksek olduğunu ortaya koymaktadır. Örneğin, bir maddede "Sanal ortamlarda başkalarının bana zarar vermemesi için bazı tedbirler alma ihtiyacı hissettiğim olur." şeklindedir. Ölçekte, .832 ile .904 arasında değişkenlik gösteren iç tutarlık katsayıları bulunmaktadır. Ölçeğin, test-tekrar test güvenirlik katsayısının ise .63 olduğu görülmüştür (Tanrıkulu, Kınay \& Arıcak, 2013).

\subsection{Verilerin Çözümlenmesi}

Veri toplama sürecinde öncelikle veri toplama araçlarını geliştiren araştırmacılardan izin istenerek ölçekler elde edilmiştir. Daha sonra veriler IBM Spss 20.0 programı ile veriler çözümlenmiştir. Ölçeklerin iç tutarlığının belirlenmesi amacıyla Cronbach katsayısı hesaplanmıştır. Siber Zorbalık Duyarlılık ölçeğine ait tek faktöre dayalı yapının (Tanrıkulu, Kınay \& Arıcak, 2013) geçerliğinin belirlenmesi amacıyla, testin uygulanabilirliğini ve muhtemel yapısını belirleyen tekrar doğrulayıcı faktör analizi yapılmıştır (Kahn, 2006; Maruyama, 1998). Doğrulayıc faktör analizi sonucu değerlendirilecek RMSEA uyum değeri, hataların ortalamasını, GFI değeri ise incelenen değişkenlerin arasında bulunan kovaryans düzeyini, IFI çokluk uyum endeksini ve CFI, kovaryans matrisiyle sıfır hipotezi göstermektedir (Şehribanoğlu, 2005; Şimşek, 2007; Yılmaz, Çelik \& Yağızer, 2009). 
Eğitim Fakültesinde Öğrenim Gören Öğretmen Adaylarının Narsisizm Düzeylerinin Siber Zorbalığa Duyarlık ve İnternet Bağımlılığı Düzeylerine Etkisi

\section{Bulgular}

Tablo 1. Narsisizm, Siber Zorbalığa Duyarlık ve İnternet Bă̆ımlılı̆̆ Arası Korelasyonlar

\begin{tabular}{lllllll}
\hline & Korelasyon & & & & & \\
\hline Değişkenler & Siber Zorbalık & İnternet Bağımııı̆ı̆ı & Narsisizm & X & Çarpıklık & Basıklık \\
\hline 1.Siber Zorbalık & - & $.32^{* *}$ & $.27^{* *}$ & 53.24 & -1.88 & 1.24 \\
2.İnternet Bağımıılığı & $.32^{* *}$ & - & $.51^{* *}$ & 42.56 & -1.02 & 1.11 \\
3.Narsisizm & $.27^{* *}$ & $.51^{* *}$ & - & 82.23 & -1.48 & 1.43 \\
\hline
\end{tabular}

$(* * \mathrm{p}<.001)$

Tablo 1'de görüldüğü üzere, narsisizm, siber zorbalığa duyarlık ve internet bağımlılığ1 arasındaki korelasyon değerlendirildiğinde, üç değişkenin de normalliğe ilişkin koşulları sağladığı bulguları elde edilmiştir. İlişkiler ele alındığında, siber zorbalığın, internet bağımlılığını $(\mathrm{r}=.32 ; \mathrm{p}<.001)$ ve narsisizmi $(\mathrm{r}=.27 ; \mathrm{p}<.001)$ pozitif yönlü anlamlı olarak yordadığı görülmüsşür. Ayrıca internet bağımlılığının da, siber zorbalığ $(\mathrm{r}=.32 ; \mathrm{p}<.001)$ ve narsisizmi $(\mathrm{r}=.51 ; \mathrm{p}<.001)$ pozitif yönlü anlamlı biçimde yordadığı sonuçlarına ulaşılmıştır.

Tablo 2. Değisşkenlere İlişkin Doğrudan- Dolaylı Yönlü Etkisel Değerler (Bootstrap Güven Aralık Değer Verileri)

\begin{tabular}{|c|c|c|c|c|c|}
\hline & Yol Katsayısı & & $\begin{array}{l}\text { Bootstrap } \\
\text { Etkisel } \\
\text { Mekanizma }\end{array}$ & $\begin{array}{l}\% 95 \\
\text { Güven } \\
\text { Aralığı }\end{array}$ & \\
\hline Yön & Siber Zorbalık & Narsisizim & Standart S. & Alt $S$. & Üst $S$. \\
\hline 1.İnternet Bağımlılığı & $.23 * *(.04)$ & $.41 * *(.07)$ & & & \\
\hline 2.Narsisizm & $.25 * *(.04)$ & & & & \\
\hline 3.İB-N-SZ & 18.18 & & $.17(.04)$ & .11 & .23 \\
\hline
\end{tabular}

$(* * \mathrm{p}<.01, \mathrm{~N}=$ Narsisizm, SZ $=$ Siber Zorbalık, İB= İnternet Bağımlılığ $)$

Tablo 2'de regresyon aracılığı ölçüm verilerine ait siber zorbalık ile internet bağımlılığı arasında narsisizm düzeylerinin etkisini belirleyen bootstrap katsayıları görülmektedir. Bulgular incelendiğinde, internet bağımlılığının siber zorbalığı $(\mathrm{BSH}=.23)$ ve narsisizm düzeylerini (BSH=.41) doğrusal açıdan etkilediği sonuçlarına ulaşılmıştır. Ayrıca, narsisizm düzeylerinin de siber zorbalığı doğrusal açıdan etkilediği görülmektedir (BSH=.25).

Dolaylı yönlü etki mekanizması değerlendrildiğinde ise, narsisizmin öğretmen adaylarının siber zorbalık ve internet bağımlılığı arasında aracılık yapan değişken olduğu görülmüştür (bootstrap katsayısı=.17, $\mathrm{SS}=.04 ; \% 95 \mathrm{GA}=.11, .23$ ). Bununla birlikte aracılık eden değişken olan narsisizmin modelde ele alınmasıyla, ilk olarak doğrusal bağıntıda ve anlamlı olan siber zorbalık 
ile internet bağımlılığı arasındaki bağlantının anlamsızlaşması sonucunda narsisizm düzeylerinin bu değişkenler üzerinde kesin aracılık ilişkisinde bulunduğu söylenebilir $\left(c^{\prime}=.04, p>.05\right)$.

Öğretmen adaylarının internet bağımlılı̆̆ ve siber zorbalık düzeyleriyle narsisizmin ilişkisel etkisinin şematik bulgularında incelendiği üzere siber zorbalık düzeylerinin öğretmen adaylarının narsisizm düzeylerini artırabildiğini ve bu artış sonucunda da internet bağımlılı̆̆ düzeylerinin de yükseldiği görülmüştür. Sunulan şemada, ilişkisel model içerisinde değişkenler ve varyanslar şemanın anlamlılı̆̆ını göstermektedir.

\section{Sonuç Tartışma ve Öneriler}

Depresyon, benlik kaygısı, stres, düşük özgüven ve özyeterlik gibi bir takım ruhsal değişkenlerle ilişkili bulunan siber zorbalık, günümüzde eğitim ortamlarında hızla büyüyen bir problem olmakta ve eğitimcilerin ve öğrencilerin psikolojilerini, güvenlerini ve yaşama dair güdülerini olumsuz açıdan etkileyebilme potansiyeli haline gelmektedir. Öğretmen adaylarının narsisizm düzeylerinin siber zorbalığa duyarlık ve internet bağımlılığı düzeylerine etkisinin incelendiği çalışmada regresyon-temelli aracılık ölçüm bulgularına ait siber zorbalık ile internet bağımlılığı arasında narsisizm düzeylerinin etkisel mekanizmasına yönelik bootstrap katsayı verileri; internet bağımlılığı düzeyinin siber zorbalığı ve narsisizm düzeylerini doğrusal olarak etkilediğini ortaya koymuştur. Aracı değişken olan narsisizmin model üzerindeki değerlendirmelerinde, doğrusallık bağıntısı bulunan ve anlamlı olan siber zorbalık ile internet bağımlılığı arasındaki ilişkide elde edilen anlamsızlaşma sonucu narsisizm düzeylerinin bu etkenleri bütünsel yordadığı ifade edilebilir.

Yapılan çalışmalarda bireylerin, nitelikli ve sağlıklı iletişim kurulabilen ortamlar bulamadıklarında bu ihtiyacını internet üzerinden gidermeye çalışabildikleri bildirilmiştir. Araştırmacılar, özellikle ailesel ilişkiler ve anne-baba yaklaşımları gibi nedenlerle yaşanan aile içi iletişim problemleri, kişilik bozuklukları, psikolojik sorunlar, arkadaş ortamı, sosyal çevrede yaşanan olumsuz etkileşimler, kişinin asosyalleşerek iletişim yollarını internet üzerinden aramasına sebep olabildiğini belirtmişlerdir. Dolayısıyla bireylerin egosantrik, narsisistik özellikleri internet bağımlılıklarını tetikleyebilmekte, böylece döngüye giren bu süreçte, bireyin internet bağımlısı olması da siber zorbalık uygulama ihtimalini artmaktadır (Sertbaş, Çuhadar \& Demirli, 2004; Terasa \& Holmbeck, 1995). Nitekim konuya ilişkin tüm çalışmalardaki kilit nokta, araştırma kapsamında ele alınan değişkenler içerisinden narsisistik kişilik yapısının internet bağımlılı̆̆ını, bu bağımlılı̆̆ın ise siber zorbalığı tetiklediği şeklinde döngüsel bir yapının bulunması şeklinde bildirilmiştir (Ang \& Goh, 2010; Elliot \& Thrash, 2001; Penney, 2002; Walrave \& Heirman, 2011).

Özellikle son yüzyılda ruh sağlığı uzmanları ve eğitimciler de, yaptıkları araştırmalarda, okul çağı çocukları arasında zorbalık olgusunun artık günümüzde teknolojik gelişmelerin yaşanması sebebiyle sanal ortamlara taşındığını ve siber zorbalığın çoğunlukla internet bağımlılarında daha fazla görüldüğünü belirtmişlerdir (Du, Jiang \& Vance, 2010, Ekşi \& Ümmet, 
2013). Ergenlik ve yetişkinlik dönemindeki bireylerle yapılan çalışmalar, narsistik kişiliğe sahip bireylerin, normal kişilik yapısına sahip bireylere oranla daha yüksek düzeyde sözel ya da fiziksel olarak saldırgan davranışlar, zorbaca hareketler gösterdiklerini ortaya koymuşlar (Temel, 2008) ve narsisizmle işyerinde yaşanan şiddet arasında direkt bir ilişkinin bulunduğunu bildirmişlerdir (Penney, 2002; Popper, 2002). Narsisistik bireylerin başkalarına karşı duydukları yoğun gereksinimleri, reddedilmeye karşı aşırı duyarlılık göstermelerine yol açmakta bu sebeple birey, derin ve bilinçdışı düzeylerde, hayranlık besledikleri çevre tarafindan yıkıma uğratılmasının intikamını gizlice alma eğilimine yol açmaktadır (Terbaş, 2004). Dolayısıyla da, narsisistik bireyler, araştırma bulgularında görüldüğü üzere gizli intikam alma yollarından biri olan siber zorbalığa yönelebilmektedirler.

Yapılan araştırmalara göre geleneksel zorbalıkla sanal zorbalık arasında bir takım benzerliklerin bulunmasına karşın (Hinduja \& Patchin, 2008; Li, 2007) sanal zorbalık ile geleneksel zorbalığın ayrımını yapan önemli bazı özelliklerin mevcut olduğu bildirilmiş̧ir (Kowalski \& Limber, 2007; Mason, 2008). Bunlara göre, geleneksel zorbalık uygulayanlar okul içerisinde ve ya iş ortamında diğer bireyler açısından tanınmaktadırlar. Ancak sanal zorbalık uygulayanların sıklıkla kim oldukları bilinmemekle beraber internet bağımlısı narsisistik kişiler olmaları onları ele verebilmektedir (Anderson \& Sturm, 2007; Chibbaro, 2007; Strom \& Strom, 2005).

Alanyazından elde edilen bu sonuçlar çalışma ile ilişkilendirildiğinde, toplum tarafından egosu destek görmeyen narsisistik bireylerin gizli intikam alma yolunu siber zorbalık yaparak gerçekleştirebileceklerini ortaya koymaktadır. Büyükşshin-Çevik ve Çelikkaleli (2010), Elliot ve Thrash, (2001), Batıün ve Hasta (2010), Griffith (1998), Horzum (2011), Tutgun, Deniz ve Moon (2011) bireylerin internet bağımlılı̆̆ı ile ruhsal durumları arasındaki ilişkiyi inceledikleri araştırmalarında, internet bağımlılığına sahip kişilerin genellikle, yalnız, hırslı ve bencil kişiler olduklarını ifade etmişlerdir. Ekşi (2012) de, çalışmasında narsisizmin "üstünlük" özelliğinin internet bağımlılığının alt bileşeni olan "sosyal izolasyon"u anlamlı olarak yordadığını belirtmiştir. Dolayısıyla internet bağımlısı kişilerin bencil bakış açısına sahip narsisistik ve zorba bireylerde görülme olasılığının fazla olması araştırma bulguları ile de desteklenen bir durumdur. Ayrica Twenge ve Campbell'a (2010) ve Ang ve Goh'un (2010), internet ortamının, narsisizm epidemiyolojisinin başlıca yayıcılarından biri olduğunu belirtmiştir. Narsist bireylerin internete düşkün olması, esasen internette bulunan sosyal sitelerde kendilerini istedikleri şekilde abartılı sunabilme imkanlarının bulunmasından dolayı oluşmaktadır, kendini olmak istediği şekilde sunan narsisistik kişi bu şekilde içsel doyuma ulaşabilmektedir. Kişisel gelişimi sunma imkânı sağlayan sitelerin narsisizmi tetiklediği ve desteklediği ayrıca narsistlerin ihtiyacı olan yüzeysel, sı ̆̆ ilişkileri desteklemesi de narsisistik kişilerin internet bağımlılığına yakın olmaları için önemli sebepler olarak bildirilmiştir.

Araştırma ışı̆̆ında, internet bağımlılı̆̆ bulunan bireylerin özdenetimlerinin yapılabilmesi için eğitimler ve destekler sağlanması önerilmektedir. Başka bireyler üstünde kontrol yürütmeyi isteme, saldırgan davranışlardan haz duyma, reel hayatta davranışa dönüştüremediği saldırganca 
düşlerini sanal ortamlarda uygulama, kendine kötü/olumsuz davranışlar sergileyen bireylerden sanal dünyada intikam almak isteme, sert mizaçlı, güçlü görünmeye çalışma, sanal ortamlarda yakalanma ve açığa çıkma riskinin oldukça düşük oluşu, kimliğini gizleme imkanının bulunması, mağdur kişiyle yüz yüze ve ya direkt iletişime geçme zorunluluğunun olmaması gibi nedenlerden kaynaklandığı için, özellikle bu durumların varlığı bilindiğinde gerekli tedbirler alınmalı, iletişim kanalları açılmalıdır.

\section{Referanslar}

Akhtar, S. (1989). Narcissistic personality disorder. Descriptive features and differential diagniosis. Psychiatry Clinic North America, 12, 505-530.

Ames, D. R., Rose, P., \& Anderson, P. C. (2006). The NPI-16 as a short measure of narcissism, Journal of Research in Personality, 40, 440-450.

Anderson, T., \& Sturm, B. (2007). Cyberbullying from playground to computer. Young Adult Library Services, Winter, 24-27.

Ang, R. P., \& Goh, D. H. (2010). Cyberbullying among adolescents: The role of affective and cognitive empathy, and gender. Child Psychiatry \& Human Development, 41 (4), 387-397.

Atay, S. (2009). Narsistik Kişilik Envanterinin Türkçeye Standardizasyonu. Gazi Üniversitesi İktisadi ve İdari Bilimler Fakültesi Dergisi 11 (1), 181-196.

Balc1, A. (2005). Sosyal bilimlerde araştırma yöntem, teknik ve ilkeler. Ankara: Pegem A.

Batıgün, A. D., \& Hasta, D. (2010). İnternet bağımlılığı: Yalnızlık ve kişilerarası ilişki tarzları açısından bir değerlendirme. Anadolu Psikiyatri Dergisi, 11, 213-219.

Bayraktar, F. (2001). İnternet kullanımının ergen gelişimindeki rolü. Yüksek lisans tezi, Ege Üniversitesi, Sosyal Bilimler Enstitüsü, İzmir.

Bhat, C. S. (2008). Cyber bullying: Overview and strategies for school counsellors, guidance officers, and all school personnel. Australian Journal of Guidance \& Counselling, 18 (1), 5366.

Büyükşahin-Çevik, G., \& Çelikkaleli, Ö. (2010). Ergenlerin arkadaş bağlllığı ve internet bağımlılığının cinsiyet, ebeveyn tutumu ve anne-baba eğitim düzeylerine göre incelenmesi. Çukurova Üniversitesi Sosyal Bilimler Enstitüsü Dergisi, 19 (3), 225-240.

Campbell, M. A. (2005). Cyber bullying: An old problem in a new guise?, Australian Journal of Guidance and Counselling, 15 (1), 68-76.

Cassidy, W., Jackson, M., \& Brown, K. N. (2009). Sticks and stones can break my bones, but how can pixels hurt me?: Students' experiences with cyber-bullying. School Psychology International, 30 (4), 383-402. 
Eğitim Fakültesinde Öğrenim Gören Öğretmen Adaylarının Narsisizm Düzeylerinin Siber Zorbalığa Duyarlık ve İnternet Bağımlılığı Düzeylerine Etkisi

Chibbaro, J. S. (2007). School counselors and the cyberbully: Interventions and implications. Professional School Counseling, 11 (1), 65-68.

Dake, J. A., Price, J. H., Telljohann, S. K., \& Funk, J. B. (2003). Teacher perceptions and practices regarding school bullying prevention. Journal of School Health, 73 (9), 347-355.

Du, Y. S., Jiang, W., \& Vance, A. (2010). Longer term effect of randomized, controlled group cognitive behavioural therapy for Internet addiction in adolescent students in Shanghai. Australian \& New Zealand Journal of Psychiatry, 44, 129-134.

Ekşi, F. (2012). Narsistik kişilik özeliklerinin internet bağımlılığı ve siber zorbalığı yordama düzeyinin yol analizi ile incelenmesi. Kuram ve Uygulamada Eğitim Bilimleri, 12 (3), 16831706.

Ekşi, F., \& Ümmet, D. (2013). Bir kişilerarası iletişim problemi olarak internet bağımlılı̆̆ı ve siber zorbalık: psikolojik danışma açısından değerlendirilmesi. Değerler Eğitimi Dergisi, 11 (25), 91-115.

Elliot, A. J., \& Thrash, T. M. (2001). Narcissism and motivation. Psychological Inquiry, 12, 216219.

Griffiths, M. (1998). Internet addiction: Does it really exist. In J. Gackenbach (Ed.), Psychology and the Internet: Intrapersonal, interpersonal, and transpersonal implication (pp. 61-75). New York: Academic Press.

Hinduja, S., \& Patchin, J. W. (2008). Cyberbullying: An exploratory analysis of factors related to off ending and victimization. Deviant Behavior, 29 (2), 129-156.

Hoff, D. L., \& Mitchell, S. N. (2009). Cyberbullying: causes, effects, and remedies. Journal of Educational Administration, 47 (5), 652-665.

Horzum, M. B. (2011). İlköğretim öğrencilerinin bilgisayar oyunu bağımlılık düzeylerinin çeşitli değişkenlere göre incelenmesi. Eğitim ve Bilim, 36, 159, 56-68.

Juvonen J., \& Gross E.F. (2008). Extending the school grounds?Bullying experiences in cyberspace. Journal of School Health, 78 (9), 496-505.

Kahn, J. H. (2006). Factor analysis in counseling psychology research, training, and practice: Principles, advances and applications. The Counseling Psychologist, 34 (5), 684-718.

Karaaziz, M., \& Erdem Atak, İ. (2013). Narsisizm ve narsisizmle ilgili araştırmalar üzerine bir gözden geçirme. Nesne Psikoloji Dergisi, 1 (2), 44-59.

Karasar, N. (2014). Bilimsel araştırma yöntemi. 27.Basım, Ankara: Nobel.

Kernberg, O. (1975). Borderline conditions and pathological narcissism. New York: Jason Aronson. 
Kowalski, R. M., \& Limber, S. (2007). Electronic bullying among middle school students. Journal of Adolescent Health, 41, 22-30.

Li, Q. (2007). Bullying in the new playground: Research into cyberbullying and cyber victimisation. Australasian Journal of Educational Technology, 23 (4), 435-454.

Li, Q., Cross, D., \& Smith, P.K. (2012). Cyberbullying in the global playground: Research from international perspectives, Q. Li, D. Cross \& P.K. Smith (Eds.), Blackwell Publishing Lt.

Maruyama, G. (1998). Basics of structural equation modeling. California: Sage.

Mason, K. L. (2008). Cyberbullying: A preliminary assessment for school personnel. Psychology in the Schools, 45 (4), 323-348.

Patchin, S., \& Hinduja, J.W. (2008). Cyberbullying: An exploratory analysis of factors related to offending and victimization. Deviant Behavior, 29 (2), 129-156.

Penney, L. (2002). Workplace Incivility and Counterproductive Workplace Behavior Cwb): What Is The Relationship And Does Personality Play A Role, Yayınlanmamış Doktora Tezi, Psychology College of Arts and Sciences University of South Florida.

Peker, A. (2014). Ergenlerin siber zorbalıkla başa çıkma davranışlarının cinsiyet ve sınıf düzeyi açısından incelenmesi, Online Journal of Technology Addiction \& Cyberbullying, 1 (1), 18-32.

Popper, M. (2002). Narcissism and attachment patterns of personalized and socialized charismatic. Leaders. Journal of Social and Personal Relationships, 19 (6), ss.798-809.

Raskin, R. N., \& Hall, C. S. (1979). A narcissistic personality inventory. Psychological Reports, 45, 590.

Raskin, R. N., \& Terry, H. (1988). A principal components analysis of the Narcissistic Personality Inventory and further evidence of its construct validity. Journal of Personality and Social Psychology, 54, 890-902.

Rivers, I., \& Noret, N. (2010). 'I h 8 u': Findings from a five-year study of text and email bullying. British Educational Research Journal, 36 (4), 643-671.

Rivers, I., \& Noret, N. (2010). Participant roles in bullying behavior and their association with thoughts of ending one's life. Crisis, 31 (3), 143-148.

Sertbaş G., Çuhadar, D., \& Demirli, F. (2004). Gaziantep üniversitesi sağlık yüksekokulu hemşirelik bölümü öğrencilerinde aile ve arkadaşlardan algılanan sosyal destek ile anksiyete düzeyi arasındaki ilişkinin belirlenmesi. Hemşirelik Forumu Dergisi, 42-8.

Smith, P. K., Mahdavi, J., Carvalho, M., Fisher, S., Russell, S., \& Tippett, N. (2008). Cyberbullying: Its Nature and impact in secondary school pupils. Journal of Child Psychology and Psychiatry, 49, 376-385.

Strom, P. S., \& Strom, R. D. (2005). Cyberbullying by adolescents: A Preliminary assessment. The Educational Forum, 70 (1), 21-36. 
Eğitim Fakültesinde Öğrenim Gören Öğretmen Adaylarının Narsisizm Düzeylerinin Siber Zorbalığa Duyarlık ve İnternet Bağımlılığı Düzeylerine Etkisi

Şehribanoğlu, S. (2005). Yapısal eşitlik modelleri ve bir uygulaması. Yüzüncü Y1l Üniversitesi, Fen Bilimleri Enstitüsü, Yüksek Lisans Tezi, Van.

Şimşek, Ö. F. (2007). Yapısal eşitlik modellemesine giriş temel ilkeler ve Lisrel uygulamaları. Ankara: Ekinoks.

Tanrıkulu, T., Kınay, H., \& Arıcak, O. T. (2013). Siber zorbalığa ilişkin duyarlılık ölçeği: Geçerlik ve güvenirlik çalışması. Trakya Üniversitesi Eğitim Fakültesi Dergisi, 3 (1), 38-47.

Temel, D. (2008). The role of perceived social problem solving, narcissim, self esteem and gender in predicting aggresive behaviors of high school students. A Thesis Submitted to the Graduate School of Social Science of Middle East Technical University.

Terasa, F., \& Holmbeck, N. G. (1995). A contextual moderator analysis of emotional autonomy and adjustment in adolescence, Child development, 66(3),793-811.

Terbaş, Ö. (2004). Kendilik psikolojisi kuramına göre kendilik bozukluklar: Bir olgu sunumu. Türk Psikiyatri Dergisi, 15 (1), 70-76.

Tokunaga, R. S. (2010). Following you home from school: A critical review and synthesis of research on cyberbullying victimization. Computers in Human Behavior, 26, 277-287.

Tutgun, A., Deniz, L., \& Moon, M. (2011). A comparative study of problematic internet use and loneliness among Turkish and Korean prospective teachers. TOJET: The Turkish Online Journal of Educational Technology, 10 (4), 14-30.

Twenge, J. M., \& Campbell, W. K. (2010). Asrın vebasl: Narsisizm illeti. (çev. Ö. Korkmaz). İstanbul: Kaknüs.

Vandebosch ,H., \& Clemput, K.V. (2008) Defining cyberbullying :A Qualitative research into the perceptions of youngsters. Cyberpsychology and Behavior, 11 (4) , 499-503.

Vandebosch, H., \& Cleemput, K.V. (2009). Cyberbullying among youngsters: Profiles of bullies and victims. New Media \& Society, 11 (8), 1349-1371.

Varjas, K., Henrich, C. C., \& Meyers, J. (2009). Urban middle school students' perceptions of bullying, cyberbullying, and school safety. Journal of School Violence, 8 (2), 159-176.

Walrave, M., \& Heirman, W. (2011). Cyberbullying: Predicting victimisation and perpetration. Children. \& Society, 25 (1), 59-72.

Wang, C.-W. (2015). Lipid droplets, lipophagy, and beyond. Biochim. Biophys. Acta-Molacular Cell Biology Lipids, 1861, 793-805.

Willard, N. (2007). Cybersafe kids, cyber-savvy teens: Helping young people learn to use the Internet safely and responsibly. California: Jossey-Bass.

Yaman, E., Eroğlu, Y., \& Peker, A. (2011). Başa çıkma stratejileriyle okul zorbalığı ve siber zorbalık. İstanbul: Kaknüs. 
Özözen Danacı, Kavaklı \& Tıkız (2018)

Yılmaz, V., Çelik, H. E., \& Yağızer, C. (2009). Çevresel duyarlılık ve çevresel davranışın ekolojik ürün satın alma davranışına etkilerinin yapısal eşitlik modeliyle araştırılması. Anadolu Üniversitesi Sosyal Bilimler Dergisi, 9 (2), 1-14.

Young, K. S. (1996). Internet addiction: The emergence of a new clinical disorder. CyberPsychology \& Behavior, 1, 237-244. 